\title{
O SENTIDO ESTÉTICO DA FORMAÇÃO DOCENTE E A CONSTITUIÇÃO DA AUTONOMIA
}

\author{
Márcia Ferreira Torres Pereira \\ Universidade Federal de Goiás - UFG (Brasil)
}

\begin{abstract}
Resumo. O presente artigo problematiza a formação de professores, especificamente no âmbito da constituição de sujeitos historicamente ativos em meio à produção de conhecimentos e aos mecanismos culturais de dominação existentes na realidade social. Objetiva-se analisar, à luz da Teoria Crítica da Escola de Frankfurt, especialmente com Theodor W. Adorno, o sentido estético da formação docente e a constituição da autonomia diante de representações e mecanismos ideológicos e formas de barbárie que incidem sobre a educação, impedindo a emancipação dos sujeitos. Trata-se de um estudo bibliográfico respaldado pelas contribuições dos teóricos Adorno e Horkheimer (1985), Adorno (2009, 2008, 2000, 1995), Benjamin (2006), Freud (2006a, 2006b, 2006c), Kant (1992), Costa (1986), Crochick (2011) e Jorge (2005). A metodologia do trabalho fundamenta-se na relação entre sujeito e objeto, universal e particular, para que não perdurem visões polarizadas e idealizadas no processo de formação do professor e da constituição de sua autonomia.
\end{abstract}

Palavras-chave: Reflexão, emancipação, formação humana.

\section{THE AESTHETIC ASPECT OF TEACHER TRAINING AND THE COMPOSITION OF AUTONONOMY}

\begin{abstract}
The present article aims to problematize the training of teachers within the scope of formation of historically active individuals among the opposing forces of knowledge production and the mechanisms of cultural dominance presently in motion. The analysis will be conducted in light of the critical theory of the Frankfurt School, especially Adorno. This study (which seeks to contribute to research in education) requires a philosophical reflection in face of representations and ideological mechanisms that inhibit the observation of contradictions found in reality, that in turn, affect the relationship between learning and development in the process of stimulating teacher autonomy. The present piece is a bibliographical study based on the contributions of theorists Adorno and Horkheimer (1985), Adorno (2009, 2008, 2000, 1995), Benjamin (2006), Freud (2006, 2006a, 2006b), Kant (1992), Costa (1986), Crochik (2011) and Jorge (2005). The method considers psychoanalytic reflection in light of the critical theory on the building of subjectivities in relation to the objective universe. In this universe education and culture legitimize forms of barbarism and prevent the conception of a true education for the emancipation of historically aware and critical individuals.
\end{abstract}

Keywords: Reflection, emancipation, human development. 


\section{EL SENTIDO ESTÉTICO DE LA FORMACIÓN DOCENTE Y EL ESTABLECIMIENTO DE LA AUTONOMÍA}

Resumen. En el presente artículo se plantea el problema de la formación de profesores en el marco de la constitución de sujetos activos en la producción de conocimientos, así como los mecanismos de dominación culturales existentes en la realidad social. Se pretende analizar, a la luz de la Teoría Crítica de la Escuela de Frankfurt, especialmente en Theodor W. Adorno, el sentido estético de la formación docente y la constitución de la autonomía ante representaciones y mecanismos ideológicos y formas de incultura que inciden sobre la educación, impidiendo la emancipación de los sujetos. Se trata de un estudio bibliográfico respaldado por las contribuciones de los teóricos Adorno y Horkheimer (1985), Adorno (2009, 2008, 2000, 1995), Benjamin (2006), Costa (1986), Freud (2006, 2006a, 2006b), Kant (1992), Costa (1986), Crochick (2011) y Jorge (2005).. La metodología del trabajo se fundamenta en la relación entre sujeto y objeto, universal y particular, con el fin de que no perduren visiones polarizadas e idealizadas en el proceso de formación y de la autonomía del profesor.

Palabras clave: Reflexión, emancipación, formación humana.

\section{Introdução}

A racionalidade moderna se configurou sobre o imediatismo da aparência, pressionando as formas de se produzir a vida social, de tal maneira que se minimiza a relevância da reflexão. Essa interferência fortalece a lógica da troca e a organização social de maneira padronizada, tornando inevitável a impossibilidade de realizar a experiência.

O conceito de experiência refere-se ao pensamento teórico de Theodor W. Adorno (2009), que não remete a uma prática subjetiva ou a uma experiência subjetiva referente à liberdade da vontade, em que o particular é destacado do seu contexto, separado da sociedade. Remete, sim, à experiência filosófica capaz de materializar a liberdade, que pressupõe autorreflexão e autoconsciência, experiências de pensamento capazes de deixar vislumbrar o menor número possível de fatores determinantes para considerar a dinâmica histórica, o movimento dialético, as contradições presentes na realidade social. Essa experiência mostra-se necessária diante do impedimento que os sujeitos sociais produzem para si mesmos, devido aos processos de participação e criação que exigem a manutenção de condutas estandardizadas e o pensamento ordenado por repetição e conformação ao existente.

Embora Adorno (1995) afirme que os sujeitos necessitam de adaptação para viver em sociedade, no âmbito da formação, esses mesmos sujeitos precisam se colocar no mundo e se conscientizar sobre como a realidade se apreende, além de refletir sobre as possibilidades de realização de novas experiências, assim como sobre os processos que contribuem para essa formação. Essas são tarefas da educação pensada em amplo sentido e também da cultura como síntese das relações sociais.

Para Adorno (1995), a experiência tem seu sentido estético, pois está relacionada aos processos que contribuem para a formação dos sujeitos sociais, envolve a leitura de mundo e o agir sobre o mundo; abrange, portanto, conhecimento e trabalho. Evidenciando a análise crítica que requer uma tensão entre o universo objetivo e a subjetividade, o conteúdo e a forma, o universal e o particular, pensar sobre o sentido da formação requer considerar alguns princípios fundamentais para possibilitar a experiência da autonomia à formação. 
Este estudo problematiza a formação de professores no âmbito da constituição de sujeitos historicamente ativos em meio à produção de conhecimentos e aos mecanismos de dominação culturais existentes na realidade social. Diante da exigência da reflexão necessária para não se correr o risco de uma formação heterônoma - que dispensa de qualquer reflexão a faculdade de conhecer, ou seja, dispensa a autonomia -, não se pode renunciar à tradição histórica, ao pensamento dialético e aos conteúdos e às formas de representação que envolvem os processos socioidentificatórios e culturais.

Partindo de tais questões, objetiva-se analisar, à luz da Teoria Crítica da Escola de Frankfurt, ${ }^{i}$ especialmente com Adorno, o sentido estético da formação docente e a constituição da autonomia diante de representações e mecanismos ideológicos e formas de barbárie que incidem sobre a educação, impedindo a emancipação dos sujeitos.

Contraditoriamente ao seu sentido originário, com base na teoria crítica da Escola de Frankfurt, os estudos de Adorno e Horkheimer (1985) apontam que a cultura contemporânea produz bens de consumo atrelados à ideia de progresso e de desenvolvimento econômico. Essa força produtiva sobre as relações sociais de produção se transforma na condição que pretende justificar as ações dos homens para a adaptação e a conformação. Ou seja, as pessoas são conduzidas ao "mercado da obediência coletiva" e sentem-se amparadas por viverem na imagem das possibilidades de um com o outro, numa compreensão distorcida de sentido sobre igualdade que confere padronização.

Nesse sentido, ao viverem em intensa desigualdade social, os sujeitos justificam suas diferenças, porém se esquecem de que a indiferença a essa situação rege a inércia sobre a vontade de compreender a realidade. No limite, refletindo sobre o que se poderia resgatar em favor de um pensamento inconformista, dado que a própria reflexão filosófica é alocada ao compromisso com as categorias que a definem, o sujeito é incapaz de transcender a reprodução desses padrões de comportamento.

No âmbito dos mundos tangíveis em que a liberdade é concebida como aquela em que o indivíduo, segundo Adorno (2009, p. 219), "persegue seus próprios fins e que coincide com o princípio da individuação não absorvidos sem mediação pelos fins sociais [...]", contraditoriamente, na sociedade moderna, preexiste uma realidade própria em que há uma representação de liberdade e que confirma uma natureza determinada como contingente do destino social de cada indivíduo singular. Dessa forma, ainda que uma realidade adjacente pudesse estar presente para potencializar o sentido de liberdade na modernidade, e que poderia afirmar o indivíduo como livre em sua forma de conduzir e produzir a vida social, a possibilidade de liberdade culmina na própria supressão da liberdade.

Essa ideia de conformação ao existente, referida pelo conceito de não liberdade, é pensada por Adorno e Horkheimer (1985). Tais autores ressaltam que a cultura impõe privações aos indivíduos, e a isso se juntam os danos da natureza não dominada para que representações alcancem finalidades mais altas sobre os limites dos sujeitos sociais. Bem conduzidos pela primazia de uma racionalidade técnica, os sujeitos se deparam com as tecnologias originadas das teorias tecnocientíficas. Aliadas à publicidade, essas teorias promovem a produção de bens capazes de apresentar tamanha facilidade que esses mesmos sujeitos são dispensados da reflexão crítica e autocrítica.

Assim, a cultura se encarrega de compensar as privações e os sofrimentos por ela construídos e impõe uma espécie de "ressurreição" necessária de outra forma de vida, apaziguada diante da iminência dos perigos possíveis. Certamente, o peso da 
existência está em não insistir na realização nem na legitimidade do sentido que pretende possuir, visto que, humilhado o pathos ontológico, nega-se a liberdade, dissolvem-se as possibilidades de autoridade e afirma-se, conforme o pensamento de Freud (2006), uma espécie de neurose infantil da humanidade diante do recalcamento exigido externamente.

Cabe ressaltar que o fato de os sujeitos serem alocados à adequação tecnológica não significa que os avanços tecnocientíficos tenham seu sistema de referência como algo previamente negativo; no entanto, segundo Adorno (1995), exprime a adequação dos indivíduos à primazia da técnica sobre o empobrecimento da capacidade de realizar algo. Essa adequação também conduz ao atrofiamento no processo de se perceber como sujeito de relações e de transcender a si mesmo de maneira a reagir para uma vontade política e como sujeito da história.

Diante do exposto, o que, entre outras razões, faz os sujeitos equipararem-se à máquina, objetificando-se, parece estar na força do trabalho útil, correspondente ao condicionamento e à ideologia que rege toda a vida social. Por isso, o dilema da formação de professores está presente nas formas de conduta intelectual que - uma vez regidas pelo compromisso e pela honestidade do empenho, exigindo reflexão sobre o que é aparentemente harmonioso - expressam-se, todavia, distanciadas de sentido. Em meio à impotência frente às teorias educacionais adequadas aos determinantes políticos e ideológicos, que correspondem à sustentação de seus estudos, de seu trabalho entre ensino e pesquisa, surge algo semelhante ao mito, que se converte em mecanismo determinante sobre toda a realidade também já previamente teorizada.

Ainda que a concepção de saber como produção deva promover autonomia à formação, há um saber que se impõe sobre todos os demais, que chama aparentemente à participação, combinada à reprodução da racionalidade moderna. Esse saber precisa de reflexões, e ele consiste em objeto de pesquisa para esclarecer sobre o que impede a educação de ir além do instituído social e culturalmente. A educação com fins à emancipação deve fazer resistência sobre si mesma enquanto avalia os mecanismos ideológicos de dominação que a mantém sob uma racionalidade instrumentalizada.

Pensar na formação de professores consiste em considerar reflexões que estabeleçam relações entre subjetividade e objetividade. A sociedade instalada no indivíduo - que é chamado à responsabilidade tanto de participar frente à produção do conhecimento quanto de tomar posições sobre concepções de mundo - é também a que conclama a conversão de sua prática educacional em um mecanismo de adaptação ao existente instituído. Essa ambiguidade incide de forma contraditória sobre o caráter objetivo do futuro professor. Sobre esse aspecto da constituição da autonomia, uma vez submetido ao mecanismo universal, é também afligido pelo veredicto social, mesmo em meio a sua altissonante resistência contra o que lhe é imposto ou quando lhe resta alternativa para algo que deve acontecer.

Para Adorno (2008), a instituição formadora pressupõe a realização da experiência como condição expressiva ao ensino e à aprendizagem, a liberdade para a expressão e, ao mesmo tempo, a independência e a relação entre ambas. Porém, no âmbito da educação escolar, os discursos se convertem em fórmulas adequadas aos mecanismos de manutenção e dominação socialmente estabelecidos. Ainda assim, tão logo haja reflexão sobre esses discursos, emergem pausas e conflitos, inseguranças a respeito do real significado da formação e da própria profissão docente, e, também, do que a realidade social permite e impede. 
Frente ao conhecimento, que se mantinha como proteção e amparo, a forma de explicação da realidade é substituída pela redução da legitimidade de aplicabilidade desses conhecimentos pela via do empobrecimento e da regressão do pensamento. Ou seja, pela primazia da forma sobre o conteúdo, essa explicação da realidade aparece como fórmula a ser seguida, com promessa de liberdade idealizada. Assim, o trabalho do professor se reduz a um discurso aprovado por regras formais.

Compõe-se, a partir daí, uma espécie de zona de contágio para assemelhar-se ao que se ajusta ao imediato, à existência e manutenção dos indivíduos à vida social determinada. Dessa forma, "[...] a sociedade integral não traz para si positivamente os indivíduos, mantendo-os como tais, mas, ao contrário, os comprime numa massa amorfa e dócil, assim cada indivíduo se atemoriza diante do processo de absorção do todo, que sente como inexorável [...]." (Adorno, 2008, p. 135).

Segundo Adorno (1995, p. 90), a representação dos professores, "por transmitirem algo já estabelecido, senão que sua função mediadora como tal, como todas as atividades de circulação, é algo de suspeito de antemão desde o ponto de vista social, atraindo certa aversão geral”. Assim, é estabelecida uma imagem negativa do professor, que perdura na ambiguidade de sua representação e na sua remuneração.

Se o indivíduo, então, sob alta pressão, estiliza a vida frente ao medo e ao sentimento de desamparo, caberia indagar: como pensar a formação de professores no âmbito da constituição de sujeitos historicamente ativos em meio às abstratas relações entre si mesmos e com a realidade? Se os objetos do conhecimento se expressam a partir de um modelo padrão justificado em relação à facilitação da aprendizagem, qual seria o sentido da formação do sujeito cognoscente?

Chama atenção, diante da questão apresentada, o compromisso da formação de professores implicada não somente na transmissão de conhecimentos ou de mecanismos facilitadores de ensino e de aprendizagem, de capacidade técnica e intelectual, mas principalmente a formação que procura a reflexão filosófica para revelar o aluno a si mesmo, apontando caminhos que sejam fecundos de valores, que agreguem responsabilidades para com o mundo objetivo, que possibilitem a autorreflexão, a crítica e a autocrítica da realidade e sobre esta, em seus mais diversos aspectos e problemas e no combate a toda e qualquer forma de exclusão social.

\section{Metodologia}

A abordagem que caracteriza este estudo é qualitativa, pois trabalha com "[...] o universo de significados, dos motivos e das aspirações, das crenças, dos valores e das atitudes." Em decorrência disso, abarca "[o] universo da produção humana que pode ser resumido no mundo das relações, das representações e da intencionalidade é objeto da pesquisa qualitativa." (Minayo, 2010, p. 21).

O procedimento de pesquisa tem como base aportes teórico-metodológicos sustentados pela Teoria Crítica da Escola de Frankfurt, utilizados para comunicar a experiência literária pela experiência da reflexão, envolvendo elementos objetivos e subjetivos do problema e a priorização de aspectos ideológicos e de dominação social e cultural da realidade. Pretende-se buscar o conhecimento de significados indispensáveis a essa compreensão, valendo-se do método que mantém a mediação entre universal e particular apresentado na obra Dialética Negativa (Adorno, 2009), sem reduzir a tensão 
dialética entre ambos, nem a distância do pensamento com relação à realidade (Carone, 2001).

\section{Resultados}

Os resultados se vinculam ao compromisso com a formação de professores que possam ultrapassar a função de transmissores de conhecimentos para incorporar a reflexão filosófica e as considerações sobre a realidade histórica e social. A autocrítica é necessária para apontar caminhos isentos de idealização, os quais fecundam valores afeitos à convivência, agregando responsabilidades subjetivas e objetivas entre os sujeitos que se implicam no processo educacional.

\section{Contribuições da psicanálise para a constituição de subjetividades}

Diante do exposto sobre as (im)possibilidades de autonomia, cabe ressaltar a psicanálise como conhecimento significativo à constituição das subjetividades e, em especial, o conceito psicanalítico de recalque, que está ligado a princípio à defesa como um mecanismo constitutivo do inconsciente, diferindo da repressão. Instaura-se, portanto, como um meio para evitar a eclosão de uma situação efetiva de desamparo do aparelho psíquico. Como a fixação precede e condiciona todo o recalque, que permanece imobilizado num estado infantil, duas forças são atuantes para a sua manutenção:

... a repulsão, que atua a partir do consciente sobre o que deve ser recalcado, e a atração exercida pelo que foi primeiramente repelido sobre tudo aquilo que possa estabelecer uma ligação. O recalque... é um processo ativo que emana do eu. Esse processo visa àqueles elementos pulsionais que primitivamente ficaram para trás, quando surge um conflito entre eles e o eu. Pode também visar certas aspirações psíquicas que ocasionam uma viva aversão (Jorge, 2005, p. 23).

O fato de haver no indivíduo um estímulo interno que produz satisfação e que se contrapõe ao que foi recalcado não impede que no recalque o desprazer seja maior do que o prazer obtido pela satisfação da pulsão. ${ }^{\text {ii }}$ Considerando que há uma força dispensada à manutenção do recalque e de seu processo contínuo, em oposição à definição freudiana da pulsão como uma força constante, os processos de recalque produzem um acentuado consumo de energia psíquica para enfrentar a ação da força constante chamada pulsão.

Seguindo a análise freudiana de que um recalque antecede tudo, e está na origem mesma da estrutura do sujeito, a força coercitiva da repressão externa pode ser um efeito do recalque, que - por afastar determinado conteúdo da consciência antes mesmo de qualquer juízo negativo, condenatório, por parte do sujeito - opera de modo automático como uma negação. Para Freud (2006a, p. 142):

A pulsão recalcada nunca deixa de se esforçar em busca da satisfação completa que consistiria na repetição de uma vivência primária de satisfação. Formações reativas e substitutivas, bem como sublimações, não bastarão para remover a tensão persistente da pulsão recalcada, sendo que a diferença de quantidade entre o prazer de satisfação que é exigida e a que é realmente conseguida, é que fornece o fator impulsionador que não permite 
qualquer parada em nenhuma das posições alcançadas, mas, nas palavras do poeta: Pressiona sempre para frente indomada.

Em relação ao estado infantil, é importante considerar que a pulsão, em geral, harmoniza-se bem com a fórmula segundo a qual uma pulsão tende para o retorno de um estado anterior. Esse caráter conservador, restituído da pulsão, está intimamente relacionado com seu aspecto repetitivo, ou seja, é do caráter conservador que emana a tendência da compulsão à repetição. Esse aspecto é independente do princípio do prazer, mas visaria retornar a uma fase específica do curso do desenvolvimento, àquilo que foi representativo naquele momento.

Para Freud (2006a), o que se repete nessas lembranças aludidas, nesse retorno, não é o mesmo, visto que o próprio movimento de retorno do recalcado marca a impossibilidade da repetição do mesmo acontecimento. Contudo, se o aparelho psíquico, para a psicanálise, funciona através do princípio do prazer, com sua tendência a reduzir as tensões, como o desprazer para o sujeito tende a se repetir de modo contínuo?

De acordo com Adorno (2009), a produção e a reprodução da vida, as quais envolvem os sujeitos sociais, são resumidas à realização reconciliada. Contra essa deformação, que privilegia a mera adaptação, resta a violência contra a barbárie civilizada. Esse movimento de resistência consistiria em uma das razões que se contrapõem aos prejuízos determinados pela cultura e pelo outro. Entretanto, a defesa contra os danos causados é atenuada pela própria pseudocultura mediante os mecanismos de dominação social, que engendram uma aparente solução.

Nesses termos, a produção de bens culturais se encarrega de promover o consumo desses meios, com os quais os sujeitos se relacionam como iguais entre si mesmos. Na intenção de compensá-los pelas privações e pelos sofrimentos causados pela convivência cultural, surgem as representações para cumprir finalidades conciliadoras aos interesses dos dominantes. Modificam-se, portanto, as relações sociais de produção, e a organização da vida em sociedade se padroniza. A conscientização de uma formação cultural, especialmente aquela que dispensa o pensamento e a liberdade, torna-se emergente para compreender os mecanismos autoritários da ideologia como "a tentativa de incutir nas pessoas uma falsa consciência e um ocultamento da realidade, além de, como se costuma dizer tão bem, procura-se impor às pessoas um conjunto de valores como se fossem dogmaticamente positivos" (Adorno, 2000, p. 80).

O discurso acerca do sujeito manifesta, por conseguinte, frente ao estado de coisas, a impossibilidade de liberdade e, mais do que isso, a negação da liberdade a partir da liberdade determinante das relações entre os sujeitos, de modo que essas relações são reconciliadas à produção e à reprodução da vida socialmente organizada. Para Adorno (1973), o fato de as pessoas ficarem no espaço da liberdade cerceada e se sentirem impotentes diante do universo objetivo prescreve, desde então, a força da ideologia.

Não seria a ideologia um componente intencional para legitimar o permanente estado de desamparo nos sujeitos, cuja condição humana é desprovida da dinâmica da experiência reflexiva, na medida em que a heteronomia configura a imaginação do irrealizável como realizável?

Frente ao desamparo, ${ }^{\text {iii }}$ o pensamento exige a permanência da idealização, de modo que a crítica é possibilidade abstrata de conteúdo. Isso ocorre devido à 
modelagem de sua constituição e da equivalência ao princípio do ser-para-todos, apesar do lugar de exceção que esse sujeito do desamparo também ocupa entre os que se sentem aparentemente amparados pela conformação às exigências da realidade objetiva. Esta acaba por ser autoritária e carregada de discursos esvaziados e obscuros diante da efetivação dos projetos de realização dos sujeitos em formação.

Por esse caminho, surgem questões atinentes sobre o que une os indivíduos e os poderes que os fazem entrar em acordo. Em Freud (2006b), o laço social pode ser provocado pelo perigo ou pelas ausências de ligações afetivas. Assim sendo, a complexidade que envolve situações de inclusão ou exclusão social dos indivíduos sugere relações com outras instâncias, baseadas no excesso de restrição que se impõe aos sujeitos e, efetivamente, de uma regulação a partir de determinações ideológicas de poder de uma cultura imposta por minorias, o que também exige renúncia para se viver em civilização.

Outrossim, o desamparo se destaca na formação docente, que, em outras palavras, funciona no mundo real como um lugar condicionado às estruturas social, política e econômica. Quando a formação é interessante, ela se expressa como instrumento ideológico para legitimar as ações dos "personagens protagonistas" e dos acontecimentos necessários aos ordenamentos conjunturalmente articulados em favor do socialmente instituído. Essa internalização corresponde à forma como os saberes são concebidos, como algo pronto e acabado, e o professor, como o mediador desses conhecimentos.

Assim se explica a relação mimética com os saberes e as relações entre docentes e discentes. Por mais que se fale em realidade, os conteúdos que impõem a adesão dos indivíduos às formas estabelecidas para a adaptação nunca foram alijados do poder conformador heterônomo, mantendo a ideia da aparente formação para a autonomia. Essas considerações precisam ser apresentadas, defendidas e postas em prática pelos educadores para evitar a manutenção da educação para a adaptação.

Segundo Adorno, "as pessoas aceitam com maior ou menor resistência aquilo que a existência dominante apresenta à sua vista e ainda por cima lhes inculca à força, como se aquilo que existe precisasse existir dessa forma." (1995, p. 178). A questão emergente surge da experiência cotidiana, que permite ver, conviver, experimentar e racionalizar constantemente contextos sociais e situações particulares de violência. Embora pareça conter uma resposta evidente quando se trata do tema, uma questão sobre o assunto não se formula como um mero pretexto, justificada por vivências do senso comum ou talvez por posturas deterministas daquilo que possivelmente nos escapa de explicação.

Para tanto, sob uma perspectiva crítica, dialética e histórica, buscou-se na teoria crítica de Adorno (2009) a sustentabilidade teórica e bibliográfica para desenvolver a temática sobre autoridade, respaldada pela análise da realidade social hegemônica que compreende o seu sentido de autoridade como dominação. O que está ocultado nos contornos da realidade objetiva contribui para a adaptação e conformação do absoluto, impondo ordenamentos gerais sobre os indivíduos.

Ao apresentar-se como racionalidade padronizada, Adorno (1995) direciona a atenção para o universo objetivo que define a forma e molda os indivíduos a meros exemplares de categorias gerais, excluindo todo o pensamento crítico. Cumpre-se apresentar, nessa medida, o problema da existência da barbárie na realidade moderna, agressividade que não se limita à violência física, mas envolve também elementos que 
são fortalecidos pela cultura objetiva e subjetivamente, que promovem a passividade dos sujeitos entre o horror e a omissão na consolidação da frieza.

Nesses termos, tomada por razões que tencionam entre universal e particular, a violência pode ser compreendida como constitutiva das condutas individuais e coletivas, configurando-se como autoridade, o que é absolutamente assumido como irracional se for considerado o sujeito do conhecimento que a realiza. $\mathrm{O}$ sujeito, sendo capaz de agir sobre a natureza e de transformá-la em bens, como também de criar as formas pelas quais as relações sociais se organizam historicamente em civilização, constrói conhecimentos ao estabelecer uma relação com o objeto a ser conhecido.

Entretanto, a relação entre sujeito e objeto se estabelece socialmente determinada pela primazia do objeto, que deve ser concebido e internalizado pelos sujeitos. Como produto da cultura moderna, a ideologia se expressa como justificativa para a dominação heterônoma sobre as consciências, conformando os sujeitos à pseudocultura que "exige sacrifícios individuais para a sua manutenção, quando ela própria não se dirige para o bem-estar de seus indivíduos e se estabelece de forma independente dos interesses racionais de seus membros" (Crochick, 2011, p. 33).

Assim como o exercício da liberdade da razão é subordinado à naturalização social, são exigidas adaptação e padronização das consciências. Nessa lógica, os conhecimentos se apresentam prontos e acabados à funcionalidade dos mecanismos de dominação social. Esse tipo de autoridade exclui a possibilidade do primado da razão no ser humano, pelo impedimento da reflexão. A ausência do pensamento crítico, substituído pelos meandros dos conceitos ou das realidades que se impõem à manutenção de tal ordenação, ampliou-se e tornou-se necessária para a não superação das representações sociais; antes, manifestou-se sob a forma de acordo, combinando a legitimidade da alienação voluntária.

Segundo Crochick (2011), a força produtiva dos conhecimentos determinantes de estereótipos, entendidos como elementos necessários à efetivação dos preconceitos, categoriza os objetos e encontra-se acorrentada aos objetivos da manutenção do status quo. Alia-se a essas metas o interesse pela expansão do consumo e do lucro como determinantes da estrutura social hegemônica. Nesse contexto, o conhecimento científico, então, torna-se cientificismo ${ }^{\text {iv }}$ e força sobre as relações sociais, comprometendo a ideia de liberdade ao estabelecer "um aprisionamento na autoconservação, tal como ela é imposta aos homens por uma sociedade que não conserva nada além da recusa da qual não se necessitaria mais" (Adorno, 2009, p. 322).

Embora os seres humanos sejam capazes de uma crítica sobre o universo objetivo, interrogando-o, por mais que se oponham a ele, são também direcionados a adaptar-se ao que lhes é alheio. Isso ocorre pois, além de a necessidade de sobrevivência ditar a preeminência das determinações sociais como aparente imanência, a lógica capitalista é estabelecida e, como racionalidade, ocupa-se de si mesma e de sua forma, obrigando os seres humanos a prescindir de sua diferenciação. Para Adorno (2009, p. 259), "o universal cuida para que o particular submetido a ele não seja melhor do que ele mesmo. Esse é o cerne de toda identidade produzida até hoje."

A proporção dada por essa afirmação carece de sentido e nos remete a uma questão psicanalítica (Freud, 2006a), na qual se pode indagar sobre a intenção e o propósito da vida humana, assim como sobre a formação de sujeitos para a emancipação. Para tal questão e suas reflexões, não se pode perder de vista a ambivalência que se mantém no esforço dos sujeitos para obter felicidade, 
empreendendo metas que visam tanto evitar o sofrimento quanto vivenciar a amplitude dos sentimentos de prazer.

Em que pese os empreendimentos para a busca da satisfação de realizações socialmente instituídas, o sofrimento se justifica em tal investimento. Nele, a violência aparece como forma apropriada entre as relações sociais, impedindo o incondicionado e as possibilidades de se pensar de outra maneira. Construídas culturalmente, essas relações se consolidam baseadas por certas significações que se apresentam como normas, modelos e valores a serem seguidos, criados pelos próprios sujeitos, sendo resultantes de uma vida social partilhada. Nesse sentido, é possível considerar a presença do conflito em que a violência é posta a serviço da manutenção social, e não como desejo instintivo de provocar o sofrimento a outrem (Costa, 1986).

Julgadas como necessárias à civilização, situações culturais manifestam-se objetivamente determinadas não pela natureza da faculdade de conhecer, mas como resposta às formas de controle e de normatização. O medo incutido nos indivíduos de pensarem por si próprios parece converter-se em dogmatismo, uma das lutas do Iluminismo contra esse princípio da Idade Média. Kant (1992) ressaltou esse aspecto ao se referir ao uso da razão como componente fundamental para compreender e conhecer a realidade, ou seja, a autonomia, que se manifesta mediante a consciência da liberdade.

Cabe efetuar uma interpolação para refletir sobre a cultura que se constrói por necessidades humanas e a sociabilidade que se expressa na educação para o desenvolvimento das disposições naturais dos indivíduos. As normas e os valores instituídos são pensados no sentido contrário quando são movidos por representações sociais, modificando seus significados.

Essa exigência de adaptação à cultura alimenta nos sujeitos a busca pelo poder, no âmbito de honrarias próprias, das posições de destaque sobre os demais, concebidas erroneamente como autonomia. Tal primazia se opõe a um "esclarecimento que se tornou muito questionável em face da pressão inimaginável exercida sobre as pessoas, seja simplesmente pela organização do mundo, seja... pelo controle planificado até mesmo de toda realidade interior" (Adorno, 1995, p. 181).

Tais situações, antes de qualquer coisa, estabelecem-se para precisar o contexto instável do qual se mantém a ideologia, que fixa os meios de captar e ordenar o real. A esse conceito de ideologia, Adorno (1973, p. 198) refere-se como "um esquema completamente abstrato da totalidade,... é falsa consciência." O vínculo às formas de ordenamento permitiu a afirmação do sujeito à ordem social dominante, estendendo-se sobre os contrários à ratificação coletiva que pertence à mesma ordem.

Nesse sentido, as adequações entusiastas derivam dos desejos de felicidade, como cita Freud (2006, p. 115), “e, portanto, são uma tentativa de apoiar suas ilusões mediante argumentos." Consequentemente, o controle justifica-se por si mesmo quando mecanismos de dominação são compartilhados aos seus objetivos e, paradoxalmente, apresentam-se como formas de segurança e amparo social que se desdobram em violência contra o pensamento.

A síntese se resolve por imposição de uma naturalização das formas de se pensar e conceber a vida, na medida em que a subjetividade é privada de reflexão e de criação. Ao mesmo tempo, essa subjetividade é deslocada para uma concepção de liberdade dos sujeitos sociais, os quais seguem os padrões consagrados do universo objetivo. A impotência, frente aos ajustamentos sociais, é escamoteada, assim como é também justificada a conformação ao que é mais fácil e mais rápido. 
No cárcere invisível dos diferentes contextos e representações, que exigem a reflexão limitada da execução de sua força e de sua manutenção, a realidade social engendra a parcialidade como totalidade e ajusta seu movimento adequado aos interesses das ideias existentes. A função fundamental desse processo consiste em desenvolver alternativas para os programas existentes, conservá-las vivas e disponíveis para que o inevitável, dissociado dos ordenamentos, mantenha o universo objetivo na dinâmica do conformismo.

Evidentemente que a compreensão da liberdade política é complexa e de modo algum unilateral. As evidências históricas registram a expansão da liberdade associada ao desenvolvimento do capitalismo. Contudo, é necessário empreender o pensamento político que rege tal compreensão: o liberalismo. O cerne desta reflexão consiste na liberdade individual conciliada com a organização social e interdependente dela, e não nas contradições que apresentam as interferências impostas culturalmente sobre a liberdade individual.

\section{Formação para a emancipação}

Se toda a rejeição passa a ser contra o diferenciado, conserva-se a norma e a padronização daquela como autoridade sobre os homens justificada como igualdade. A justaposição do conceito incorre no prevalecimento de universalidade e generalidade, sem perceber as contradições presentes na concepção de igualdade. Tendo a norma caráter geral, evidentemente que sua aplicação está sujeita a falhas. Entretanto, corrigir a falha ou as falhas possíveis sobre o universo do conceito, genericamente formulado, exige desconsiderar o próprio sentido de uma ação excludente, uma vez que ela se encontra predeterminada. Isso significa dizer que a igualdade padronizada como norma presente no imaginário social se apresenta como equidade.

Quanto mais coerentemente, porém, os sistemas jurídicos são elaborados, tanto mais se tornam incapazes de absorver aquilo que tem sua essência na recusa à absorção. O sistema jurídico racional consegue regularmente rebaixar a pretensão de equidade que constituía o corretivo da injustiça no interior do direito ao nível do protecionismo, de um privilégio desigual. A tendência para tanto é universal, segue lado a lado com o processo econômico que reduz os interesses particulares ao denominador comum de uma totalidade que permanece negativa porque, em virtude de sua abstração constitutiva, distancia-se dos interesses particulares a partir dos quais, porém, ao mesmo tempo se compõe. A universalidade que reproduz a conservação da vida a coloca concomitantemente em risco, em um nível cada vez mais ameaçador. A violência do universal que se realiza não é como Hegel pensava idêntica à essência dos indivíduos em si, mas sempre também contrária a ela. (Adorno, 2009, p. 259).

A equidade se expressa, portanto, a serviço da igualdade para retificar o seu sentido universal. Embora apareça a necessidade da exigência do conceito de igualdade para registrar o poder da norma social, exigindo padronização, a própria equidade se manifesta com a função de ajuste para a formulação da igualdade generalizada. Com a pretensão de dar significado ao conceito de igualdade, a equidade é compreendida de maneira conjuntural, validando um conceito análogo e genérico. Isso permite, ainda, que a ideia de formação docente seja compreendida apenas como integração que incorpora os elementos de dominação do universo objetivo para que o diferenciado 
possa se adaptar ao universalmente instituído, justificando o direito de igualdade, ao mesmo tempo em que ressalta a necessária diversidade e a possibilidade de exclusão.

Em condições sociais, cuja incontestável figura da autoridade do professor deve ser compreendida como centro de referência, a formação do professor, entretanto, é direcionada pela força hegemônica do universo objetivo, o que faz com que essa autoridade se expresse como a repetição dessa dominação. A coerção das condições objetivas é interpretada como convicção coletiva e estabilizadora dos vínculos sociais cobrados pelo preço da alienação. Essa condição do professor se assemelha ao sujeito da psicanálise, que é, conforme cita Freud (2006), resultante do efeito da repressão, manifestação inconsciente afetada pelas relações sociais associadas aos mecanismos sociais de controle existentes.

Nesses termos, a individualidade resvala para o individualismo. Sobre este conceito, segundo Crochick (2011), o livre pensamento torna-se comprometido à causalidade do mundo empírico. O sujeito é afirmado no objeto, e a razão é negada, pois a distância entre o sujeito e o objeto do conhecimento desaparece, assim como a possibilidade de perceber e julgar racional e historicamente a coletividade humana. Provocado pelas exigências de autocontrole e competência diante dos efeitos da padronização e da perda de seu espaço culturalmente determinado, ou seja, no monopólio de minorias, o professor é conformado às exigências da cultura, que, de acordo com Adorno (1995), contrariam o sentido da autonomia, da criação e da capacidade de realizar a experiência da reflexão.

As justificativas, que convertem o prazer em facilidades para o não exercício do pensamento, são dadas pela primazia da técnica sobre os sujeitos, como um espelho do universo social. "Um mundo como o de hoje, no qual a técnica ocupa posição chave, produz pessoas tecnológicas afinadas com a técnica... As pessoas tendem a tomar a técnica pela coisa mesma... esquecendo... que ela é o prolongamento do braço humano" (Adorno, 1995, p. 118).

Com objetivos de privilegiar os moldes voltados às coisas prontas, coisas em si mesmas, a formação de professores carece de reflexão sobre a formação de subjetividades, considerando que as pessoas têm se convertido em "pessoas completamente frias, que devem negar mesmo em seu íntimo a possibilidade de amar.... E a capacidade de amar que, porventura, sobreviva nelas, volta-se, invariavelmente, para os meios" (Adorno, 1995. p. 119).

Há uma estrutura totalizadora, que historicamente exerce o controle ao qual tudo deve se ajustar de maneira global. O sentido autoritário desse ordenamento fornece articulação necessária à manutenção de sua consolidação. "As oportunidades dos indivíduos... são determinadas segundo o lugar em que os grupos sociais a que pertençam estejam realmente situados na estrutura hierárquica de comando do capital" (Mészáros, 2011, p. 98).

Misturam-se às marcas dos tempos de intensa atividade da modernidade, especificamente do mercado consumidor, a apropriação de um espaço de promoção cultural partilhada e, por que não dizer, uma cultura direcionada pela lógica do capital econômico para sua manutenção e expansão. ${ }^{\vee} \mathrm{O}$ centro do processo civilizatório é também governo, poder objetivo e "motor propulsor" de aceleração do desenvolvimento político e econômico. Justifica-se como racionalidade sobre os modos de conceber e de produzir a vida em sociedade, qual seja: o consumo. 
Numa época em que se difundem mesclas de pensamentos reorganizadores de intencionalidades outras, mas cujos conteúdos se manifestam como figuras aparentes de combate à violência, alguns conceitos parecem resolver as possíveis "brechas" de desvelamento das contradições do próprio sistema social. Conceitos como "inclusão" e "diversidade" tentam responder ao combate ideológico da violência social. "Mas, se há algo que pode ajudar contra a frieza como condição de desgraça, seria a compreensão das condições que determinam seu surgimento e o esforço de combatê-las desde a sua formação no âmbito individual" (Adorno, 1995, p. 121).

$\mathrm{O}$ sujeito parece ter perdido a medida de ordenamento do mundo e se funde nele por uma mimese, tributando-lhe confiança devido ao seu desamparo, ao tempo que também dele se separa. Para viver na modernidade, a propósito de seus desafios e mitos, Benjamim (2006, p. 73) ressalta que a "multidão se consome pelas maravilhas, as quais, não obstante, a Terra lhe deve". Nesse aspecto, o distanciamento do mundo, paradoxalmente tão atraente e confortável, resolve-se na alienação dos sujeitos presos ao consumo, fragmento de uma unidade ideal. Nisso se verificam os valores metabolizados em mercadorias, embora haja uma aparente liberdade de possuir e de escolher.

Nesses termos, Adorno afirma a necessidade do conhecimento dos mecanismos subjetivos que afirmam a formação de autoridades que subordinam pessoas como servos, perpetuando o direito de servidão: "esta é, antes de mais nada, a consciência que permanece cega frente a tudo o que veio-a-ser, frente a toda compreensão da própria racionalidade, e absolutiza o que é-assim" (Adorno, 1995, p. 118).

\section{Considerações finais}

Mais que uma justificativa política de ordenamento social ou de conquista de direitos humanos, a emergência da formação de professores não deveria se abster dos conceitos de autoridade e de autonomia, que podem ser entendidos como confissão de fraqueza educacional. Embora a educação tenha sua finalidade na sustentabilidade da vida social, empenha-se, contraditoriamente, para a banalização da formação humana. Isso se dá devido à insignificância das relações entre sociedade e educação quando se trata da formação para a adaptação social, uma vez que, para promover transformações estéticas e ético-políticas, ela se encontra interditada por mediações idealizadas e conformistas à formação de sujeitos históricos.

Com efeito, uma realidade que tem como primado a violência escamoteada pelos discursos políticos favoráveis às ações educacionais conjuga-se à naturalização do conformismo, visto que tais ações são também necessárias à funcionalidade dos ordenamentos sociais. Entretanto, existindo a conservação de ideologias no âmbito da formação docente, isso não significa que a negação dessa realidade ou a opção por um ensino que se empenhe contra a perpetuação da ideologia possa se constituir numa resposta ou possibilidade de transformação. Há de se considerar quais são os vínculos já legitimados à manutenção dos condicionamentos dessa formação, além de ressaltar a força dos mecanismos de ordem política e administrativa determinados no interior das instituições.

A formação docente que considere o conceito de autonomia pressupõe a formação de consciências frente à realidade historicamente determinada. Por isso, para 
problematizar sobre os sujeitos que se pretende formar, será necessário considerar as relações sob uma perspectiva dialética, entre sujeito e objeto, entre universal e particular, entre teoria e práxis. Isso significa dizer que "a composição orgânica dos homens de modo algum se refere unicamente a destrezas técnicas especializadas, mas igualmente o seu oposto aos elementos da condição natural que por certo já derivaram da dialética da sociedade e nela agora decai” (Adorno, 2008, p. 237).

Pensando a condição em que se encontra a formação docente, carece compreender que as capacidades intelectuais são objetivadas conforme as condições que a levam à coisificação das mentes. Cair numa atitude meramente contemplativa perante o conhecimento é permitir que a subjetividade, a capacidade de reflexão e expressão se convertam em um mecanismo abstrato, no ponto culminante da alienação. Nessa organização em que o ego se torna impotente, ou mero ponto de referência para manifestar-se com reações prontas, isentas de mediação, mecânicas e alheias, registra-se o crescimento dos antagonismos. A identidade do professor inicia-se no processo de sua formação e repousa na não identificação com essas realidades, no ainda não ocorrido e na travessia da dinâmica da totalidade.

\section{Referências}

Abbagnano, N. (2007). Dicionário de Filosofia. São Paulo: Martins Fontes.

Adorno, T. W. (2009). Dialética negativa. São Paulo: Zahar.

Adorno, T. W. (2008). A mínima moralia: reflexões a partir da vida lesada. Rio de Janeiro: Beco do Azougue.

Adorno, T. W. (2000). Educação e emancipação. Rio de Janeiro: Paz e Terra.

Adorno, T. W. (1995). Palavras e sinais: modelos críticos 2. Petrópolis: Vozes.

Adorno, T. W. (1973). Temas básicos da sociologia. Tradução de Álvaro Cabral. São Paulo: Cultrix.

Adorno, T. W. e Horkheimer, M. (1985). A Dialética do Esclarecimento. Rio de Janeiro, Jorge Zahar.

Benjamin, W. (2006). O anjo da história. Belo Horizonte: Autêntica.

Carone, F. B. (2001). Subordinação e coordenação: confrontos e contrastes. 6. ed. São Paulo: Ática.

Costa, J. F. (1986). Violência e psicanálise. Rio de Janeiro: Graal.

Crochick, J. L. (2011). Preconceito e inclusão. Revista do Instituto Cultural judaico Marc Chagall, 3(1). 
Freud, S. (2006a). O futuro de uma ilusão; o mal-estar na civilização e outros trabalhos (1927-1931). In: Obras psicológicas completas de Sigmund Freud. Rio de Janeiro: Imago Editora, v. XXI.

Freud, S. (2006b). A história do movimento psicanalítico, artigos sobre a metapsicologia e outros trabalhos (1914-1916). In: Obras psicológicas completas de Sigmund Freud. Rio de Janeiro: Imago Editora, v. XIX.

Freud, S. (2006c). Além do princípio de prazer, psicologia de grupo e outros trabalhos Psicologia das massas e análise do ego (1920-1922). In: Obras psicológicas completas de Sigmund Freud. Rio de Janeiro: Imago Editora, v. XIV.

Jorge, M. A. C. (2005). Fundamentos da psicanálise: de Freud a Lacan. São Paulo: Zahar.

Kant, I. (1992). Crítica da razão prática. São Paulo: Martins Fontes.

La Planche, J. e Pontalis, J. B. (2004). Diccionario de pisicoanalisis. Buenos Aires: Paidós.

Mészáros, I. (2000). Para além do capital: rumo a uma teoria da transição. São Paulo: Boitempo.

Minayo, M. C. S. (2010). Pesquisa social: teoria, método e criatividade. 29. ed. Petrópolis: Vozes.

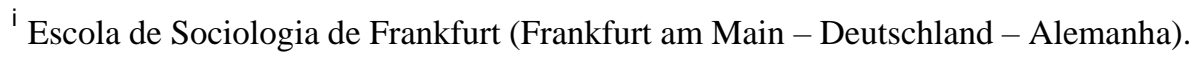

ii Pulsão: uma pulsão nos aparecerá como um conceito fronteiriço entre o psíquico e o somático, como um representante psíquico dos estímulos que provêm do interior do corpo e alcançam a mente, como uma medida de exigência de trabalho que é imposta à mente em consequência de sua ligação com o corporal. (Freud, 2006b, p. 117).

iii "a incapacidade de ajudar-se a si mesmo „,estado de desamparo ${ }^{\text {ee }}$ [por não dispor] de condições de safar-se por si só.” (La Planche e Pontalis, 2004, p. 57).

iv Atitude de quem atribui importância preponderante à ciência em comparação com as outras atividades humanas, ou de quem considera que não há limites para a validade e a extensão do conhecimento científico. Nesse sentido, o termo equivale ao positivismo, mas com a conotação pejorativa (Abbagnano, 2007).

` O capitalismo é uma das formas possíveis da realização do capital, uma de suas variantes históricas, presente na fase caracterizada pela generalização da subsunção real do trabalho ao capital. Assim como existia capital antes da generalização do sistema produtor de mercadorias (de que é exemplo o capital mercantil), do mesmo modo se pode presenciar a continuidade do capital após o capitalismo, por meio da constituição daquilo que Mészáros denomina "sistema de capital pós-capitalista", que teve vigência na
} 
URSS e nos demais países do Leste Europeu, durante várias décadas do século XX (Mészáros, 1995, p. 44).

Data de recebimento: $18 / 02 / 2016$

Data da revisão: $06 / 11 / 2018$

Data do aceite: 29/12/2018 